\title{
FUNGICIDAL EFFECT OF LIPPIA ALBA ESSENTIAL OIL ON A WHITE-ROT FUNGUS
}

\author{
K.V.N. Geromini ${ }^{1}$, F.B. Roratto ${ }^{1}$, F.G. Ferreira ${ }^{1}$, J. Camilotti1, T.M.A. Vidigal ${ }^{1}$, J.S. Valle ${ }^{1}$, \\ N.B. Colauto ${ }^{1}$, G.A. Linde ${ }^{1, \wedge}$
}

\begin{abstract}
Lippia alba is a plant that has antifungal activity against Aspergillus, Penicillium and Trichoderma genera as well as against human pathogenic microorganisms; however, there are no records on its effect on basidiomycetes which are responsible for white rot of wood. The objective of this study was to evaluate the antifungal activity of $L$. alba for the control of the white-rot fungus Pleurotus ostreatus. From L. alba leaves, essential oil (EO) was extracted by hydrodistillation, alcoholic extract (AE) was obtained through alcoholic maceration, and aqueous extract (QE) from aqueous infusion. Each extract was added to several culture media to evaluate the fungicidal effect on $P$. ostreatus. AE and $\mathrm{QE}$ do not have fungicidal activity. P. ostreatus does not survive $\mathrm{EO}$ when concentrations are higher than $1,0 \mathrm{~mL} \mathrm{~L}^{-1}$ in malt extract liquid culture medium, or higher than $9,0 \mathrm{~mL} \mathrm{~L}^{-1}$ in particulate sawdust solid culture medium. The physical state of the cultivation medium affects the fungicidal action of EO. In surfaces subject to greater volatility, the minimum fungicidal concentration of the EO is $25,0 \mathrm{~mL} \mathrm{~L}^{-1}$. Altogether, L. alba EO is a potential alternative of biological control of basidiomycetes of white rottenness in wood.
\end{abstract}

Keywords: Alcoholic maceration, antifungal activity, aqueous infusion, hydrodistillation, Pleurotus ostreatus.

\section{INTRODUCTION}

Wood has been used as building material because of its properties such as aesthetic appearance, low density, low thermal expansion, and desirable mechanical strength, with indoor and outdoor applications (Wang et al. 2005). Biodegradation of wood by fungi is a problem for wooden structures and forest management. Durability is one of the most important considerations for the use of wood in construction. Poor durability has often been recognized as one of the disadvantages of wood (Wang et al. 2005, Cheng et al. 2008).

Pleurotus ostreatus (Jacq. ex Fr.) P. Kumm. (Pleurotaceae) is a white-rot basidiomycete worldwide distributed and usually grows on hardwood. P. ostreatus ability to degrade lignocelluloses efficiently is related with mycelial growth that allows nutrient transportation like nitrogen and iron from nutrient-rich areas to nutrient-poor areas (Hammel 1997). Also, for this fungus two types of extracellular enzymatic systems are described: the hydrolytic system and the oxidative and extracellular ligninolytic system. The first comprises hemicellulases and cellulases, that degrades polysaccharide and the last comprises lignin peroxidases, manganese peroxidases and laccases which degrades lignin and opens phenyl rings (Sánchez 2009).

P. ostreatus has been extensively studied mostly about the biochemistry of its mushroom and mycelium productions (Cohen et al. 2002). Furthermore, this fungus grows on different substrates without changing the morphology of the mycelium. Because of this, P. ostreatus is a good model to test new methodologies and prospect new compounds to control basidiomycetes.

\footnotetext{
${ }^{1}$ Molecular Biology Laboratory, Postgraduated Program in Biotechnology Applied to Agriculture, Paranaense University, Praça Mascarenhas de Moraes, 4282, 87.502-210, Umuarama-PR, Brazil

^Corresponding author: gianilinde@unipar.br

Received: 21.06.2013 Accepted: 09.03,.2014
} 
Synthetic fungicides are used to control basidiomycetes in the wood industry, however, they may damage the environment, reduce air quality, must not be used for indoor and can affect animals' and/or humans' health (Tascioglu et al. 2013). Therefore, the search for safer phytochemicals with lower environmental damage and animal toxicity is a primordial demand (Schultz and Nicolas 2000, Wedge et al. 2000).

One alternative of biological control is the utilization of extracts of plants that have antifungal activity (Şen and Yalçın 2010). Lippia alba is an aromatic plant, broadly cultivated and commercialized in Latin America such as in Mexico, Colombia, Paraguay, Brazil, Uruguay and Argentina (UNCTD, 2005). The leaves of this bush are used mainly because of its sedative, antidepressant, digestive, antihemorrhoid, anti-asthmatic and stomach-relieving properties (Hennebelle et al. 2008).

Hennebelle et al. (2008) reported that the main antimicrobial activities of $L$. alba essential oil are against Bacillus, Lactobacillus, Enterococcus, Staphylococcus, Streptococcus, Enterobacter, Escherichia, Klebsiella, Pseudomonas, Cryptococcus and Trichophyton genera. The antifungal activity against human pathogens was reported for genera such as Candida and Trichophyton for the citral and myrcene-citral chemotypes (Oliveira et al. 2006). Glamočlija et al. (2011) reported antifungal activity against Aspergillus, Fusarium, Penicillium and Trichoderma genera. Although several studies analyzed the extracts of $L$. alba, specifically the essential oil, for microbiological control in plants (Rozwalka et al. 2008), human health (Pessini et al. 2003, Tempone et al. 2008) and green molds (Glamočlija et al. 2011), although the use of this plant or its extracts have not been reported for the control of basidiomycetes. Thus, the objective of this study was to evaluate the antifungal activity of $L$. alba on the mycelium of $P$. ostreatus for the control of wood white rottenness.

\section{MATERIALS AND METHODS}

Leaves of L. alba (Mill.) N. E. Br. ex Britton \& P. Wilson (Verbenaceae), were collected in the morning at nine from March to May, 2009 in the Medicinal Plant Garden of the Paranaense University - Campus of Umuarama - Brazil. Dirt was removed with tap water and the leaves were stored in polyethylene plastic bags at $-20^{\circ}$ C. P. ostreatus U2-9 from the Laboratory of Molecular Biology of the Paranaense University was used.

\section{Extracts of $L$. alba leaves}

L. alba leaves were submitted to hydrodistillation to obtain essential oil (OE), to alcoholic maceration to obtain alcoholic extract (AE), and to aqueous infusion to obtain aqueous extract (QE). Defrosted leaves $(100 \mathrm{~g})$ were transferred to a Clevenger apparatus for hydrodistillation for one hour in order to extract EO that was filtered $(0,22 \mu \mathrm{m})$ and stored at $-20^{\circ} \mathrm{C}$. EO yield was determined by considering the EO volume extracted from $100 \mathrm{~g}$ of $L$. alba leaves, expressed in percentage of oil volume $(\mathrm{mL})$ per leave mass $(100 \mathrm{~g})$ multiplied by 100 . AE was prepared by macerating defrosted leaves (1:2) in alcohol $950 \mathrm{~mL} \mathrm{~L}^{-1}$. The mixture was agitated manually for $15 \mathrm{~min}$ and was kept undisturbed for three days. AE was filtered (14 $\mu \mathrm{m})$, filtered again $(0,22 \mu \mathrm{m})$ and stored at ambient temperature $\left(25^{\circ} \mathrm{C}\right)$ in the dark. QE was produced by infusion of defrosted leaves in water $(1: 10)$ at $100^{\circ} \mathrm{C}$ for $15 \mathrm{~min}$. The infusion was filtered $(14 \mu \mathrm{m})$, filtered again $(0,22$ $\mu \mathrm{m})$ and immediately used.

\section{Antifungal activity in liquid or solid medium}

P. ostreatus mycelium was transferred to $20 \mathrm{~g} \mathrm{~L}^{-1}$ malt agar extract (MAE) previously autoclaved at $121{ }^{\circ} \mathrm{C}$ for $20 \mathrm{~min}$. The growth was carried out at $28^{\circ} \mathrm{C}$ during seven days. Dishes containing homogenous mycelium without sectioning were selected as inoculum.

One MAE disk (6 mm diameter) containing mycelium was transferred to the center of a Petri dish with MAE or to the well of a microplate containg $1,5 \mathrm{~mL}$ of $20 \mathrm{~g} \mathrm{~L}^{-1}$ malt extract (ME). Both culture media were previously autoclaved at $121{ }^{\circ} \mathrm{C}$ for $20 \mathrm{~min}$ and cooled at ambient temperature. After five days of mycelial growth at $28{ }^{\circ} \mathrm{C}, 500 \mu \mathrm{L}$ of an aqueous mixture containing 0,$1 ; 2,5$ or $25,0 \mathrm{~mL} \mathrm{~L}^{-1}$ of EO or AE or QE of $L$. alba leaves was added. The aqueous mixture was manually homogenized for $15 \mathrm{~s}$ in liquid medium and for 
the Petri dish it was distributed all over the surface on the solid medium. The negative control was done with $500 \mu \mathrm{L}$ of autoclaved ultrapure water.

After five days, the mycelium of each treatment was transferred to MAE and kept at $28^{\circ} \mathrm{C}$ for 20 days to verify the mycelial viability. The mycelium that grew visually was considered viable.

\section{Addition of emulsifier to the essential oil mixture}

For the liquid culture medium, it was observed that for the highest concentrations of EO there was a separation of phases with oil concentration on the surface. Thus, the use of an emulsifier was evaluated to keep the water-oil mixture stable in the liquid culture medium. Therefore, a MAE disk (6 mm diameter) containing the mycelium was transferred to the well of a microplate containing 1,5 $\mathrm{mL}$ of ME. After five days of mycelial growth at $28^{\circ} \mathrm{C}, 500 \mu \mathrm{L}$ of an aqueous mixture of EO of $L$. alba leaves with polysorbate- 80 (P80) was added to obtain the final EO concentration of $0 ; 0,1 ; 0,5 ; 1 ; 2,5 ; 5 ; 10$ or $25 \mathrm{~mL} \mathrm{~L}^{-1}$ in the liquid culture medium. For each EO concentration, the final concentrations of $\mathrm{P} 80$ of $0 ; 1 ; 10 ; 40$ or $60 \mathrm{~mL} \mathrm{~L}^{-1}$ were tested, totalizing 40 treatments (combination of EO and P80). After five days of contact of the mixture, the mycelium in the liquid culture medium was transferred to MAE and kept at $28{ }^{\circ} \mathrm{C}$ for 20 days, with record of mycelial viability by visual growth.

\section{Antifungal activity of $L$. alba EO in particulate solid culture medium}

Sawdust of Eucalyptus spp was kept in water at $90^{\circ} \mathrm{C}$ for $120 \mathrm{~min}$. Next, the water excess was removed and $1,5 \mathrm{~g}$ of sawdust was transferred to $15 \mathrm{~mL}$ Falcon tube with lid and autoclaved at $121^{\circ} \mathrm{C}$ for $60 \mathrm{~min}$. Then, the culture medium was inoculated with a MAE disk (6 mm diameter) containing mycelium and kept at $28^{\circ} \mathrm{C}$ for 14 days.

After the total colonization of the particulate culture medium, $1 \mathrm{~mL}$ of $\mathrm{P} 80$ solution $60 \mathrm{~mL} \mathrm{~L}^{-1}$ containing $0 ; 0,5 ; 1 ; 2 ; 3 ; 4 ; 5 ; 6 ; 7 ; 8 ; 9 ; 10 ; 12,5$ or $15 \mathrm{~mL} \mathrm{~L}^{-1}$ of EO was added. The particulate culture medium was kept with EO for $1 ; 1,5 ; 3 ; 6 ; 12 ; 24 ; 48 ; 120$ or $240 \mathrm{~h}$. After each period of time, part of the colonized medium was transferred to MAE and kept at $28^{\circ} \mathrm{C}$ for 30 days to verify visually the mycelium growth viability. The mycelium that grew was considered viable. All experiments were replicated ten times.

\section{RESULTS AND DISCUSSION}

L. alba EO extraction yield was $1,5 \mathrm{~mL} \mathrm{~kg}^{-1}$ of leaves. This value is within the range of EO extraction yield for this plant that varies from $0,8 \mathrm{~mL} \mathrm{~kg}^{-1}$ (Shukla et al. 2009) to $16,0 \mathrm{~mL} \mathrm{~kg}^{-1}$ (Hennebelle et al. 2006). L. alba EO can vary in quantity and in composition according to climate, soil composition, plant organ, age and vegetative cycle stage (Hennebelle et al. 2006). Hennebelle et al. (2008) reported as well that yield and composition of $L$. alba $\mathrm{EO}$ are highly influenced by chemotypes. This variability of yield and chemical composition of EO causes difficulty for the cultivation and commercialization of this plant (Manica-Cattani et al. 2009). One way to minimize this problem would be the use of micropropagation of $L$. alba clones, standardization of cultivation and extraction methods to obtain chemical uniformity (Gupta et al. 2001, Biasi and Costa 2003).

The addition of $1,0 \mathrm{~mL} \mathrm{~L}^{-1}$ of EO in ME had a fungicidal effect on $P$. ostreatus and in MAE, the inhibition only occurred with the addition of $25,0 \mathrm{~mL} \mathrm{~L}^{-1}$ of EO (Table 1). EO are easily volatilized (Guenther 1948) and the difference of the fungus inhibition in function of the physical state of the culture medium may be related to the greater evaporation area in the Petri dishes with consequent reduction of EO concentration and fungicidal activity. 
Table 1. Mycelial viability of Pleurotus ostreatus grown on liquid or solid malt extract culture medium for five days at $28^{\circ} \mathrm{C}$, followed by the addition of different concentrations $\left(\mathrm{mL} \mathrm{L}^{-1}\right)$ of essential oil (EO), alcoholic extract (AE) or aqueous extract (QE) of Lippia alba leaf extract.

\begin{tabular}{cccccccc}
\hline Extract concentration in culture medium $\left(\mathbf{m L ~ L ~}^{-1}\right)$ & \multicolumn{3}{c}{$\begin{array}{c}\text { Solid culture } \\
\text { medium with }\end{array}$} & \multicolumn{3}{c}{$\begin{array}{c}\text { Liquid culture } \\
\text { medium with }\end{array}$} \\
& EO & AE & QE & EO & AE & QE \\
\hline 0 & + & + & + & + & + & + \\
1 & + & + & + & - & + & + \\
2,5 & + & + & + & - & + & + \\
25 & - & + & + & - & + & + \\
\hline
\end{tabular}

Absence (-) or presence (+) of mycelial growth in the viability test.

Table 1 shows the results of fungicidal effect on P. ostreatus in MAE or ME with addition of different concentrations of $\mathrm{EO}, \mathrm{AE}$ or $\mathrm{QE}$ of $L$. alba leaves. $\mathrm{AE}$ and $\mathrm{QE}$ did not have any fungicidal activity at any concentration of culture medium. However $L$. alba EO presented fungicide activity for the fungus.

Alcoholic and aqueous extract of Acacia mollissima, Schinopsis lorentzii and Pinus brutia are described as fungicidal against rot-wood fungi (Tascioglu et al. 2013). The main compounds in these extracts are tannins, flavanoids, lignans, stilbens, terpenes and terpenoids also described as fungicidal. In our work, based on the lack of fungicidal activity of $\mathrm{AE}$ and $\mathrm{QE}$, the extracts composition was undetermined. For the non-volatile compounds of $L$. alba leaves are described three iridoids, geniposidic acid, caryoptoside, 8-epi-loganin and mussaenoside. Also are described phenyletanoid/phenylpropanoid, flavonoid glycosides and biflavonoids (Hennebelle et al. 2008). Thus, future studies should investigate the composition of the extracts and even different ways of extraction. Moreover, other plant parts - as roots and stems - could also be evaluated. Because only EO showed a fungicidal effect (Table 1), it was selected for the subsequent experiments.

The addition of $\mathrm{P} 80$ to the liquid culture medium did not cause any change in fungal growth surviving (Table 2). However, the EO antifungal activity was affected by the concentration of emulsifier added. When EO was added to $0,1 \mathrm{~mL} \mathrm{~L}^{-1}$ of liquid culture medium, there was no inhibition, except for the treatment without P80 addition (Table 2). This indicates that P80 provided higher homogeneity to the liquid culture medium with EO, decreasing the anaerobic condition caused by the $\mathrm{EO}$ accumulation on top of the culture medium. To obtain a higher emulsifying effect in the liquid culture medium the concentration of $60,0 \mathrm{~mL} \mathrm{~L}^{-1}$ of P80 was chosen for the subsequent experiments

Table 2. Mycelial viability of Pleurotus ostreatus grown on liquid malt extract culture medium ( $20 \mathrm{~g}$ $\mathrm{L}^{-1}$ ) for five days at $28^{\circ} \mathrm{C}$, followed by the addition of different concentrations of Lippia alba essential oil with different concentrations of polysorbate- 80 .

\begin{tabular}{cccccc}
\hline $\begin{array}{c}\text { Essential oil concentration in liquid } \\
\text { culture medium }\left(\mathbf{m L ~ \mathbf { L } ^ { - 1 }}\right)\end{array}$ & \multicolumn{5}{c}{ Polysorbate-80 concentration in liquid } \\
culture medium & $\left(\mathbf{m L} \mathbf{~ L}^{-1}\right)$ & $\mathbf{6 0}$ \\
\hline 0 & $\mathbf{0}$ & $\mathbf{1}$ & $\mathbf{1 0}$ & $\mathbf{4 0}$ & $\mathbf{6 0}$ \\
0,1 & + & + & + & + & + \\
0,5 & - & + & + & + & + \\
1 & - & - & - & + & + \\
2,5 & - & - & - & - & - \\
5 & - & - & - & - & - \\
10 & - & - & - & - & - \\
25 & - & - & - & - & - \\
\hline
\end{tabular}

Absence (-) or presence (+) of mycelial growth in the viability test 
P. ostreatus is mainly a saprophyte that decomposes wood and, therefore, simulating the development of this fungus on sawdust is appropriate to evaluate the antifungal activity of $L$. alba EO under conditions close to the natural ones. In this culture medium, the fungicide effect occurred at $\mathrm{EO}$ concentration over $8 \mathrm{~mL} \mathrm{~L}^{-1}$ with $60 \mathrm{~mL} \mathrm{~L}^{-1}$ of P80 exposed for any time (Table 3).

Even the minimal exposure of one hour of the EO caused a fungicide effect which is promising for the use on the wood industry because there was no temporary fungistatic effect. It is verified that the EO concentration is the main factor in the fungicidal effect because lower or equal $\mathrm{EO}$ concentrations to $8,0 \mathrm{~mL} \mathrm{~L}^{-1}$ had neither fungicidal nor fungistatic effect, even after $240 \mathrm{~h}$ of exposure (Table 3 ).

Table 3. Mycelia viability of Pleurotus ostreatus grown on particulate sawdust culture medium for 14 days at $28{ }^{\circ} \mathrm{C}$ followed by the addition of different concentrations of Lippia alba essential oil with $60 \mathrm{~mL}$

$\mathrm{L}^{-1}$ polysorbate- 80 for different periods.

\begin{tabular}{|c|c|c|c|c|c|c|c|c|c|}
\hline \multirow{2}{*}{$\begin{array}{l}\text { Essential oil concentration in the } \\
\text { culture medium }\left(\mathrm{mL} \mathrm{L} \mathrm{L}^{-1}\right)\end{array}$} & \multicolumn{9}{|c|}{ Time (h) } \\
\hline & 1 & 1,5 & 3 & 6 & 12 & 24 & 48 & 120 & 240 \\
\hline 0 & + & + & + & + & + & + & + & + & + \\
\hline 0,5 & + & + & + & + & + & + & + & + & + \\
\hline 1 & + & + & + & + & + & + & + & + & + \\
\hline 2 & + & + & + & + & + & + & + & + & + \\
\hline 3 & + & + & + & + & + & + & + & + & + \\
\hline 4 & + & + & + & + & + & + & + & + & + \\
\hline 5 & + & + & + & + & + & + & + & + & + \\
\hline 6 & + & + & + & + & + & + & + & + & + \\
\hline 7 & + & + & + & + & + & + & + & + & + \\
\hline 8 & + & + & + & + & + & + & + & + & + \\
\hline 9 & - & - & - & - & - & - & - & - & - \\
\hline 10 & - & - & - & - & - & - & - & - & - \\
\hline 12,5 & - & - & - & - & - & - & - & - & - \\
\hline 15 & - & - & - & - & - & - & - & - & - \\
\hline
\end{tabular}

Absence (-) or presence (+) of mycelial growth. 
The chemical analysis of $L$. alba EO used in this work was characterized by gas chromatography and mass spectrometry analysis, and the structure of the main compounds were confirmed by hydrogen-1 and carbon-13 nuclear magnetic resonance spectroscopy and published on Glamočlija et al. (2011). The main found components were geranial $(50,94 \%)$ and neral $(33,32 \%)$ and $97,69 \%$ of the EO chemical constituents were identified and classified as citral chemotype (Glamočlija et al. 2011). Geranial seems to be the main fungicidal component of $L$. alba EO. According to Shukla et al. (2009), geranial from $L$. alba caused inhibition of growth on $76 \%$ of 17 tested fungi, whereas, at the same concentration, neral component presented inhibition only on $22 \%$. It indicates that the high geranial concentration of $L$. alba EO may explain the EO antifungal activity.

As reported by Burt (2004) an important characteristic of EO and their components is their hydrophobicity, which enables them to partition the lipids of the bacterial cell membrane and mitochondria, disturbing the structures and making them more permeable (Sikkema et al. 1994). Leakage of ions and other cell contents can then occur. The EO mechanism of action is similar to other phenolics; this is generally considered to be a disturbance of the cytoplasmic membrane, disrupting the proton motive force, electron flow, active transport and coagulation of cell contents (Denyer and Hugo 1991, Sikkema et al. 1995, Davidson 1997). EO components also appear to act on cell proteins as ATPases enzymes embedded in the cytoplasmic membrane (Knobloch et al. 1989). Therefore, different EO compounds can act differently and affect the antifungal activity. Thus, it is important to develop studies that evaluate the antifungal activity of isolated EO compounds. Such prospects may direct the synthesis of less harmful compounds to health and environment. Moreover, the EO composition may vary according to the genotype and phenotype of the plant (Silva et al. 2006), directing the control of culture conditions to maintain the composition and antifungal activity of $L$. alba EO.

The physical state of the culture medium is another important factor of the fungicidal activity; therefore, lower EO concentrations $\left(0,5\right.$ to $\left.1,0 \mathrm{~mL} \mathrm{~L}^{-1}\right)$ were needed for the liquid culture medium whereas higher concentrations $\left(9,0\right.$ to $\left.25,0 \mathrm{~mL} \mathrm{~L}^{-1}\right)$ were needed for the solid culture medium (Table 1, 2 and 3). Particulate solid sawdust culture medium has natural wood capillaries (Segerholma and Claessona 2008) where the mycelium can grow. These capillaries provide physical protection to the mycelium and make the contact with EO difficult. Thus, a higher EO concentration is needed to cause the antifungal effect regarding the liquid culture medium. The development of applications for L. alba EO is still not well-explored. Rao et al. (2000) reported antifungal activity against sugarcane pathogens, Park et al. (2007) and Lee et al.(2008) reported bioactivity against phytopathogens and dermatophytes, and Glamočlija et al. (2011) reported antifungal activity against green moulds (Trichoderma ssp., Fusarium ssp., Aspergillus ssp. and Penicillium ssp.) genus Geels et al. (1988) reported that Trichoderama, Aspergillus and Penicillium species can cause mushroom production losses and suggested the use of $L$. alba EO instead broad spectrum systemic fungicides to control those green moulds. Glamočlija et al. (2011) indicates L. alba EO to control green molds with minimum inhibitory concentration (MIC) in a range of 0,3 to $1,25 \mathrm{mg} \mathrm{mL}^{-1}$ and minimum fungicidal concentration (MFC) in a range of 0,6 to $1,25 \mathrm{mg} \mathrm{mL}^{-1}$. Results obtained in our study under similar conditions with liquid media showed that just 1,0 $\mathrm{mL} \mathrm{L}^{-1}$ (circa de $0,5 \mathrm{mg} \mathrm{mL}^{-1}$ ) of L. alba $\mathrm{EO}$ has fungicidal activity on P. ostreatus.

In this work we showed that the L. alba essential oil may be further explored to develop wood decay preservative agents or fumigants. Some possibilities are described like: isolate the main fungicidal compound and encapsulate the volatile to prevent evaporation and allow the release of the active compound only with humidity, which plays an important role in promoting fungal growth (Voda et al. 2003). 
The biodegradation of wood by basidiomycetes is a serious problem for increase the use of wood (Cheng $e t$ al. 2008). The main basidiomycete recognized worldwide as major wood decay fungi are white rot fungi such as Coriolus versicolor, Lenzites betulina, Pycnoporus coccineus, Trichaptum abietinum, Oligoporus lowei, Schizophyllum commune and Pleurotus ostreatus (Wang et al. 2005, Cheng et al. 2008, Yen and Chang 2008, Yen et al. 2008, Hsu et al. 2009, Tascioglu et al. 2013) and brown-rot fungus such as Coniophora puteana (Voda et al. 2003), Fomitopsis palustris, Gloeophyllum trabeum, Laetiporus sulphureus, Antrodia taxa, Fomitopsis pinicola and Phaeolus schweinitzii (Xu and Goodell 2001, Wang et al. 2005, Yen and Chang 2008, Cheng et al. 2008, Tascioglu et al. 2013). In this work we use the white-rot $P$. ostreatus - that prefer hardwoods - as a model for in vitro tests. Future experiments should expand the use of $L$. alba EO as fungicidal to other important white-rot fungi and also to brown-rot fungi to protect softwoods.

\section{CONCLUSIONS}

The alcoholic and aqueous extracts of $L$. alba leaves have no antifungal activity against $P$. ostreatus. The essential oil has fungicidal effect at concentrations that are higher than $1,0 \mathrm{~mL} \mathrm{~L}^{-1}$ in liquid culture media of malt extract or higher than $8,0 \mathrm{~mL} \mathrm{~L}^{-1}$ in particulate sawdust solid culture media. The physical state of the culture medium affects the fungicidal activity of essential oil. On surfaces where the essential oil is more volatile, the minimum concentration for fungicidal activity is $25,0 \mathrm{~mL} \mathrm{~L}^{-1}$. L. alba essential oil is a potential alternative for biological control against wood white-rot fungus.

\section{ACKNOWLEDGEMENTS}

The authors thank the Paranaense University and the Postgraduate Program in Biotechnology Applied to Agriculture of the Paranaense University.

\section{REFERENCES}

Biasi, L.A.; Costa, G. 2003. Vegetative propagation of Lippia alba. Ciência Rural 33(3):455-459.

Burt, S. 2004. Essential oils: their antibacterial properties and potential applications in foods-a review. International Journal of Food Microbiology 94(3):223-253.

Cheng, S.S.; Liu, J.Y.; Chang, E.H.; Chang, S.T. 2008. Antifungal activity of cinnamaldehyde and eugenol congeners against wood-rot fungi. Bioresource Technology 99(11):5145-5149.

Cohen, R.; Persky, L.; Hadar, Y. 2002. Biotechnological applications and potential of wood-degrading mushrooms of the genus Pleurotus. Applied Microbiology and Biotechnology 58(5):582-594.

Davidson, P.M. 1997. Chemical preservatives and natural antimicrobial compounds. In: Doyle, M.P.; Beuchat, L.R.; Montville, T.J. (eds). Food microbiology: fundamentals and frontiers. ASM, Washington, USA, pp. 520-556.

Denyer, S.P.; Hugo, W.B. 1991. Mechanisms of antibacterial action - a summary. In: Denyer, S.P.; Hugo, W.B. (eds). Mechanisms of action of chemical biocides. Blackwell, Oxford, UK, pp. 331-334.

Geels, F.P.; Van de Geijn, J.; Rutjens, A.J. 1988. Pests and diseases. In: Van Griensven, L.J.L.D. (ed). The cultivation of mushrooms. Mushroom Experimental Station, Horst, Netherlands, pp. 397-398. 
Glamočlija, J.; Soković, M.; Tešević, V.; Linde, G.A.; Colauto, N.B. 2011. Chemical characterization of Lippia alba essential oil: an alternative to control green molds. Brazilian Journal of Microbiology 42(4):1537-1546.

Guenther, E. 1948. The essential oils. D. Van Nostrand Company, New York.

Gupta, S.K.; Khanuja, S.P.S.; Kumar, S. 2001. In vitro micropropagation of Lippia alba. Current Science 81(2):206-210.

Hammel, E.K. 1997. Fungal degradation of lignin. In: Cadisch, G.; Giller, K.E.; (eds). Driven by nature: plant litter quality and decomposition. CAB International, London, United Kingdom, pp. 33-45.

Hennebelle, T.; Sahpaz, S.; Dermont, C.; Joseph, H.; Bailleul, F. 2006. The essential oil of Lippia alba: analysis of samples from French overseas departments and review of previous works. Chemistry and Biodiversity 3(10):1116-1125.

Hennebelle, T.; Sahpaz, S.; Joseph, H.; Bailleul, F. 2008. Ethnopharmacology of Lippia alba. Journal of Ethnopharmacology 116(2):211-222.

Hsu, F.L.; Chen, P.S.; Chang, H.T.; Chang, S.T. 2009. Effects of alkyl chain length of gallates on their antifungal property and potency as an environmentally benign preservative against wood-decay fungi. International Biodeterioration and Biodegradation 63(5):543-547.

Knobloch, K.; Pauli, A.; Iberl, B.; Weigand, H.; Weis, N. 1989. Antibacterial and antifungal properties of essential oil components. Journal of Essential Oil Research 1(3):119-128.

Lee, Y.S.; Kim, J.; Shin, S.C.; Lee, S.G.; Park, I.K. 2008. Antifungal activity of Myrtaceae essential oils and their components against three phytopathogenic fungi. Flavour and Fragrance Journal 23(1):23-28

Manica-Cattani, M.F.; Zacaria, J.; Pauletti, G.; Atti-Serafini, L.; Echeverrigaray, S. 2009. Genetic variation among south Brazilian accessions of Lippia alba Mill. (Verbenaceae) detected by ISSR and RAPD markers. Brazilian Journal of Biology 69(2):375-380.

Oliveira, D.R.; Leitão, G.G.; Santos, S.S.; Bizzo, H.R.; Lopes, D.; Alviano, C.S.; Alviano, D.S.; Leitão, S.G. 2006. Ethnopharmacological study of two Lippia species from Oriximina, Brazil. Journal of Ethnopharmacology 108(1):103-108.

Park, M.J.; Gwak, K.S.; Yang, I.; Choi, W.S.; Jo, H.J.; Chang, J.W.; Jeung, E.B.; Choi, I.G. 2007. Antifungal activities of the essential oils in Syzygium aromaticum (L.) Merr. et Perry and Leptospermum petersonii Bailey and their constituents against various dermatophytes. Journal of Microbiology 45(5):460-465.

Pessini, G.L.; Holetz, F.B.; Sanches, N.R.; Cortez, D.A.G.; Dias-Filho, B.P.; Nakamura, C.V. 2003. Avaliação da atividade antibacteriana e antifúngica de extratos de plantas utilizados na medicina popular. Revista Brasileira de Farmacognosia 13(1):21-24.

Rao, G.P.; Singh, M.; Singh, P.; Singh, S.P.; Catalan, C.; Kapoor, I.P.S.; Singh, O.P.; Singh, G. 2000. Studies on chemical constituents and antifungal activity of leaf essential oil of Lippia alba (Mill). Indian Journal of Chemical Technology 7(6):332-335. 
Rozwalka, L.C.; Lima, M.L.R.Z.C.; Mio, L.L.M.; Nakashima, T. 2008. Extracts, decoctions and essential oils of medicinal and aromatic plants in the inhibition of Colletotrichum gloeosporioides and Glomerella cingulata isolates from guava fruits. Ciência Rural 38(2):301-307.

Sánchez, C. 2009. Lignocellulosic residues: biodegradation and bioconversion by fungi. Biotechnology Advances 27(2):185-194.

Schultz, T.P.; Nicholas, D.D. 2000. Naturally durable heartwood: evidence for a proposed dual defensive function of the extractives. Phytochemistry 54(1):47-52.

Segerholma, I.; Claessona, J. 2008. Unexpected experimental results for capillary suction in wood: analysis on the fibre level. Wood Material Science and Engineering 3(3-4):109-118.

Şen, S.; Yalçın, M. 2010. Activity of commercial still waters from volatile oils production against wood decay fungi. Maderas. Ciencia y Tecnología 12(2):127-133.

Shukla, R.; Kumar, A.; Singh, P.; Dubey, N.K. 2009. Efficacy of Lippia alba (Mill.) N.E. Brown essential oil and its monoterpene aldehyde constituents against fungi isolated from some edible legume seeds and aflatoxin B1 production. International Journal of Food Microbiology 135(2):165-170.

Sikkema, J.; De Bont, J.A.M.; Poolman, B. 1994. Interactions of cyclic hydrocarbons with biological membranes. Journal of Biological Chemistry 269(11):8022-8028.

Sikkema, J.; De Bont, J.A.M.; Poolman, B. 1995. Mechanisms of membrane toxicity of hydrocarbons. Microbiological Reviews 59(2):201-222.

Silva, N.A.; Oliveira, F.F.; Costa, L.C.B; Bizzo, H.R.; Oliveira, R.A. 2006. Chemical characterization of erva cidreira's essential oil (Lippia alba (Mill.) N. E. Br.) grown in Ilheus, Bahia State, Brazil. Revista Brasileira de Plantas Medicinais 8(3):52-55.

Tascioglu, C.; Yalcin, M.; Sen, S.; Akcay, C. 2013. Antifungal properties of some plant extracts used as wood preservatives. International Biodeterioration and Biodegradation 85(1):23-28.

Tempone, A.G.; Sartorelli, P.; Texeira, D.; Prado, F.O; Calixto, I.A.R.L.; Lorezi, H.; Melhem, M.S.C. 2008. Brazilian flora extracts as source of novel antileishmanial and antifungal compounds. Memórias do Instituto Oswaldo Cruz 103(5):443-449.

UNCTD. United Nations Conference on Trade and Development. 2005. Market Brief in the European Union for Selected Natural Ingredients Derived from Native Species: Lippia alba prontoalivio, erva cidreira, juanilama, melissa. [on line] <http://www.biotrade.org/ResourcesPublications/biotradebrief-lippiaalba.pdf $>$. [Accessed on: 28 November 2012].

Voda, K.; Boh, B.; Vrtaä, M. 2003. Effect of the antifungal activity of oxygenated aromatic essential oil compounds on the white-rot Trametes versicolor and the brown-rot Coniophora puteana. International Biodeterioration and Biodegradation 51(1):51-59.

Wang, S.Y.; Chen, P.F.; Chang, S.T. 2005. Antifungal activities of essential oils and their constituents from indigenous cinnamon (Cinnamomum osmophloeum) leaves against wood decay fungi. Bioresource Technology 96(7):813-818. 
Wedge, D.E.; Galindo, J.C.G.; Macias, F.A. 2000. Fungicidal activity of natural and synthetic sesquiterpene lactone analogs. Phytochemistry 53(7):747-757.

Xu, G.; Goodell, B. 2001. Mechanisms of wood degradation by brown-rot fungi: chelator-mediated cellulose degradation and binding of iron by cellulose. Journal of Biotechnology 87(1):43-57.

Yen, T.B.; Chang, H.T.; Hsieh, C.C.; Chang, S.T. 2008. Antifungal properties of ethanolic extract and its active compounds from Calocedrus macrolepis var. formosana (Florin) heartwood. Bioresource Technology 99(11):4871-4877.

Yen, T.B.; Chang, S.T. 2008. Synergistic effects of cinnamaldehyde in combination with eugenol against wood decay fungi. Bioresource Technology 99(1):232-236. 